\title{
Improving the Skid Resistance and Surface Texture of Asphalt Pavement Using AMIR Compactor Technology
}

\author{
Luciana Girardi Omar* and Abd El Halim Omar Abd El Halim \\ Department of Civil and Environmental Engineering, Carleton University, Canada
}

Submission: July 01, 2018; Published: August 02, 2018

*Corresponding author: Luciana Girardi Omar, Department of Environmental and Civil Engineering, Carleton University, Canada; Tel: 613- 8055732; Email: lucianaomar@cmail.carleton.ca

\begin{abstract}
The asphalt compaction process is one of the most important factors affecting long term performance of asphalt pavements. The compaction of asphalt pavements reduces the air voids in the asphalt mixture and repositioning the aggregate particles more closely together in order to create a denser and more effective asphalt mixture. A good compaction provides mechanical stability and resistance to deformation, while reducing the permeability of the mixture and prolonging durability. In practice for decades, the conventional method of compaction of asphalt pavements adopted by the Canadian road agencies encompasses three stages with one specific roller for each stage. Although, this compaction method satisfies the road authority's requirement of densification, the design objectives of asphalt pavements are rarely met because the pavements deteriorate earlier than the expected design service life. Further, the conventional method of compaction also affects pavement surface textures by changing the arrangement of the aggregate particles during compaction the asphalt. In response, an innovative single-roller compaction method with a prototype roller, known as the Asphalt Multi Integrated Roller (AMIR), was tested in Ontario. This paper examines and compares the performance of two new field trials compacted with the AMIR and the conventional compaction rollers. The results confirm that the AMIR is capable of providing single stage compaction with better and uniform values of pavement textures, skid resistance and macrotexture. Thus, AMIR finished roads ensure safer roads.
\end{abstract}

Keywords: AMIR compactor; Pavement textures, Skid resistance; Macrotexture

Abbreviation: AMIR: Asphalt Multi Integrated Roller; LWT: Locked Wheel Tester; MTO; Ontario Ministry of Transportation; TAC: Transportation Association of Canada

\section{Introduction}

Compaction of asphalt pavements is defined as the process of reducing the air voids in the asphalt mixture and enhancing the interlock between the aggregate particles through rearranging them more closely together in order to create a denser and more effective asphalt mixture [1]. In Ontario, Canada, since 1970, the currently conventional compaction method encompasses three stages with one specific roller for each stage. The main result of using three types of rollers is the attempt to treat the formation of hairline cracks (check cracks) caused by the vibratory steel roller used in the first stage of compaction, the breakdown stage. In the second stage of compaction, the intermediate stage, a pneumatic roller is used due to the false belief that it treats the hairline cracks caused in the first stage. In the third stage, the finish stage, a static smooth roller smoothens the tire marks left by the pneumatic roller in the second stage [2].
Although the current conventional compaction method satisfies the road authority's requirement of densification, the design objectives of asphalt pavements are rarely met because the pavements deteriorate earlier than the expected design service life (15 to 20 years), despite significant improvements to asphalt mix quality, testing methods, contract specification, and workmanship [3]. The main reason for premature deterioration of asphalt pavements is related to deficiencies in the conventional compaction method that induces check cracking and results in pavement distresses such as surface cracks, low compaction at unsupported edges and longitudinal joints, and loss of fine aggregates. Furthermore, the resulted cracks permit water to penetrate the surface of the top asphalt layer leading to additional damage caused by freeze/thaw cycles and stripping. 


\section{Civil Engineering Research Journal}

For over 150 years, the highway construction industry and road authorities have been searching for a satisfactory single stage compaction method. Due to the limitations of existing rollers and a lack of improvement in roller design, no alternative method has yet provided satisfactory enough results to replace the abovedescribed three-stage method that has now been in practice in Ontario for over 55 years.

In response, research at Carleton University since the 1980s led to the development of an innovative compaction method with a prototype roller known as the Asphalt Multi Integrated Roller (AMIR). The AMIR prototype has been tested in several field trials in Canada and Australia [4-8]. Results have shown that asphalt layers compacted with the AMIR performed better than those compacted with the conventional rollers. The AMIR does not induce check cracks and does not require an additional set of rollers. Further, the compaction density is achieved in a single stage, which reduces construction costs and increases efficiency. The main objective of this paper is to compare asphalt pavement surface textures, skid resistance (microtexture) and macrotexture, of asphalt lanes on a bridge when compacted with two different rollers: the AMIR and conventional steel wheel roller.

\section{AMIR Compactor}

The Asphalt Multi Integrated Roller (AMIR) is an innovative compaction roller that was developed after studies on reflection cracking of bituminous overlays. These studies showed that the use of steel rollers in the conventional compaction method induced check cracking due to a conflict between the rollers' geometry and composition and the relative rigidity of the soft asphalt layer. The AMIR concept is based on the principle that modifying the geometry and material of the roller would improve the overall compaction of the asphalt layers, the pavement joints, and unsupported edges. The change of both the cylindrical shape and the stiffer material of the drums; the often roller check cracks could be eliminated. The AMIR is a multi-layered rubber belt that creates a single flat contact area for compaction. The belt is flexible, which provides a closer match in rigidity to the asphalt surface and thus prevents induced hairline cracks such as those caused by conventional compaction. The AMIR prototypes are shown in Figure $1 \& 2$. The AMIR IV is fourth generation of AMIR stages and is termed TRAK to differentiate it from the first prototype invented in the early 1980's.

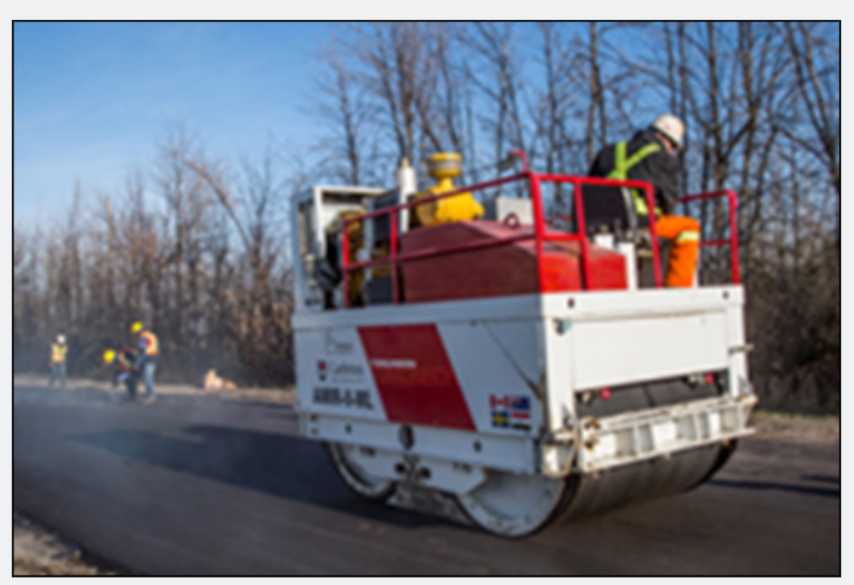

Figure 1: AMIR I Prototype (2000's).

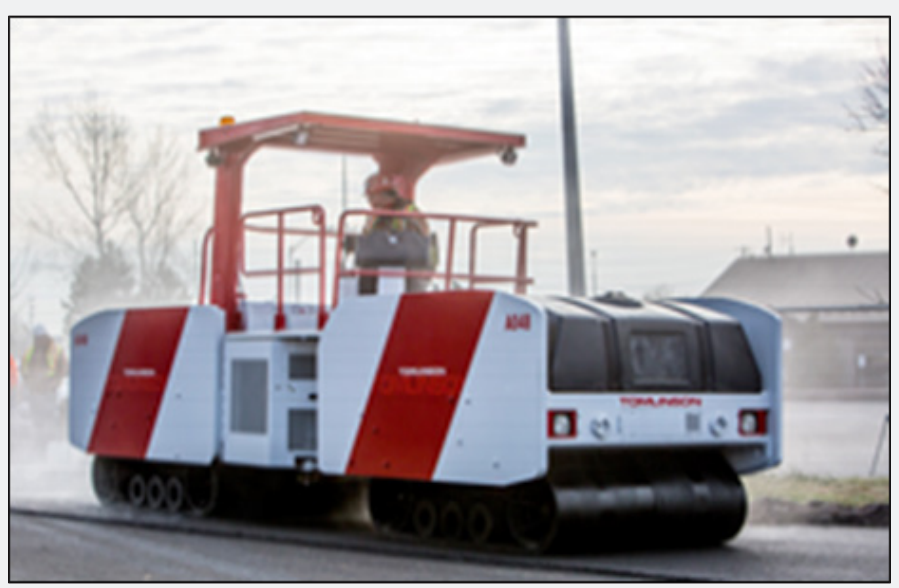

Figure 2: AMIR IV (TRAK) Prototype (2017). 
The AMIR's performance has been extensively tested in Canada and Australia. Results have shown that asphalt pavement sections on highways and bridge decks compacted with the AMIR exhibited a crack-free surface with tighter texture, greater uniformity in density distribution, better all around mechanical properties, less permeable and higher stripping resistance when compared to the same asphalt mixes compacted using conventional compaction method [4-8].

\section{Pavement surface texture}

Pavement texture is defined by the ISO 13473-2 [9] as "the deviations of the pavement surface from a true planar surface, with a texture wavelength less than $0.5 \mathrm{~m}$ ". The texture wavelength describes the horizontal dimension of the roughness of a texture profile expressed in metres $(\mathrm{m})$ or millimetres (mm). Pavement deviations are categorized into four levels according to texture wavelength, where:

A. Microtexture: wavelength $<0.5 \mathrm{~mm}$, amplitude $0.001 \mathrm{~mm}$ to $0.5 \mathrm{~mm}$

B. Macrotexture: wavelength $>0.5 \mathrm{~mm}$ to $50 \mathrm{~mm}$, amplitude $0.1 \mathrm{~mm}$ to $20 \mathrm{~mm}$,

C. Megatexture: wavelength $>50 \mathrm{~mm}$ to $500 \mathrm{~mm}$, amplitude $0.1 \mathrm{~mm}$ to $50 \mathrm{~mm}$,

D. Roughness or unevenness: wavelength $>500 \mathrm{~mm}$.

Pavement texture affects the interface between the tires of a vehicle and the pavement surface. Pavement friction, or pavement skid resistance, is provided through a combination of two surface texture properties, microtexture and macrotexture [10,11]. Megatexture and roughness are associated with the ride-related qualities of pavement surface, such as ride-related quality, rolling resistance, level of noise, vibration, fuel consumption, and tire wear $[12,13]$. Microtexture is associated with the scale texture of the individual aggregate and is dependent on the physical nature of the aggregates (surface texture of aggregates) or the fines in the mixture [14]. Poor levels of microtexture imply a low level of skid resistance at most speeds [15]. Macrotexture is related to the height, width, angularity, and density of macro projections above the surface. Macrotexture is usually assessed by the depth of the peaks of large aggregates. Macrotexture allows the drainage of water through channels formed by large aggregates. The level of pavement macrotexture is arguably correlated with good levels of skid resistance at high speeds. Limited macrotexture associated with polished aggregate and combined with speed, tire pressure, and water depth affects the susceptibility of a vehicle to hydroplaning [9]. Hydroplaning occurs when a thin film of water separates the tire and the pavement and the vehicle skids without any resistance.

\section{Reference values for skid resistance and macrotexture}

Microtexture levels cannot be measured directly in the field at high speeds because there is no device capable of capturing wavelengths smaller than $0.5 \mathrm{~mm}$ Therefore, skid resistance measurements are used as a surrogate measurement of microtexture $[16,17]$. There is a variety of devices that can be used to measure skid resistance in the field and in the laboratory. In Ontario, the locked wheel tester (LWT) is the most common device for measuring skid resistance at the network level. The Transportation Association of Canada (TAC) and the Ontario Ministry of Transportation (MTO) recommend a minimum level of skid resistance of 31 for Canadian roadways [18,19]. In Europe, skid resistance measured using the British pendulum tester should be between 42 and 60 BPN after temperature correction [20]. In Australia, the Transport and Road Research Laboratory recommends a minimum BPN of 55 for wet surfaces with ADT over 2000 [21]. The Australian Department of Transportation recommends a BPN of 45 for rural roads with maximum vehicle speed of $100 \mathrm{~km} / \mathrm{h}$ [22].

Macrotexture measurements can be taken using several methods, including a volumetric test using a sand patch apparatus, outflow metres, and methods based on non-contact profiling techniques that employ laser base devices. In Ontario, laserbased devices are the most commonly used devices for measuring macrotexture at the network level. In the laboratory and for local projects, a common approach for macrotexture measurements is the volumetric method using a sand patch apparatus. In Canada, there is no minimum standard or recommendation for macrotexture levels for new pavements. However, other countries have set minimum standards for macrotexture regarding safety concerns. For instance, the Australian Department of Transportation recommends a texture depth of $0.40 \mathrm{~mm}$ to $0.8 \mathrm{~mm}$ for dense graded asphalts $(10 \mathrm{~mm}$ or larger $)$ and $1.2 \mathrm{~mm}$ for open graded asphalt for new surfacing [23]. In the United Kingdom, the Design Manual for Roads and Bridges recommends an investigation of skid resistance on road surfaces that exhibit a macrotexture depth level of less than $0.80 \mathrm{~mm}$ in order to avoid the combination of low skid resistance and low texture depth [24].

\section{Material and Methods}

Measurement of pavement textures, skid resistance and macrotexture asphalt pavement lanes compacted with the AMIR and conventional steel rollers were conducted on two new asphalt pavements located in the city of Ottawa and on a bridge in the city of Kingston, in Ontario, Canada. The measurements of the road sections located in city of Ottawa (Site 1) were taken in November of 2017. The road section consisted of a two-lane undivided road with 200 metres long. The road section was subdivided into five sub sections of 40 metres. Each lane was 3.60 metres wide. The asphalt mix used was the Superpave FC2. In Ottawa road section, the AMIR was compared with the use of Oscillating steel drum and pneumatic rollers for 100 meters and a vibratory steel drum and pneumatic rollers for the remaining 100 meters.

The measurements of asphalt deck located on the bridge in the city of Kingston (Site 2) consisted of a four-lane undivided road with approximately 75 metres long. Each lane was 3.60 metres wide. The road section was subdivided into five sub-sections of 15 


\section{Civil Engineering Research Journal}

metres. The asphalt mix used was the HL1. The sub-sections were identified as section A, B, C, D and E. For each sub-section, two points were measured on the lane compacted with the AMIR and two points were measured on lane compacted with a conventional steel roller. The two points were located on the centre and on left wheel path of the lanes. Figure $3 \& 4$ show the layout of the road sections and the locations of the sub sections and points where the measurements were taken.

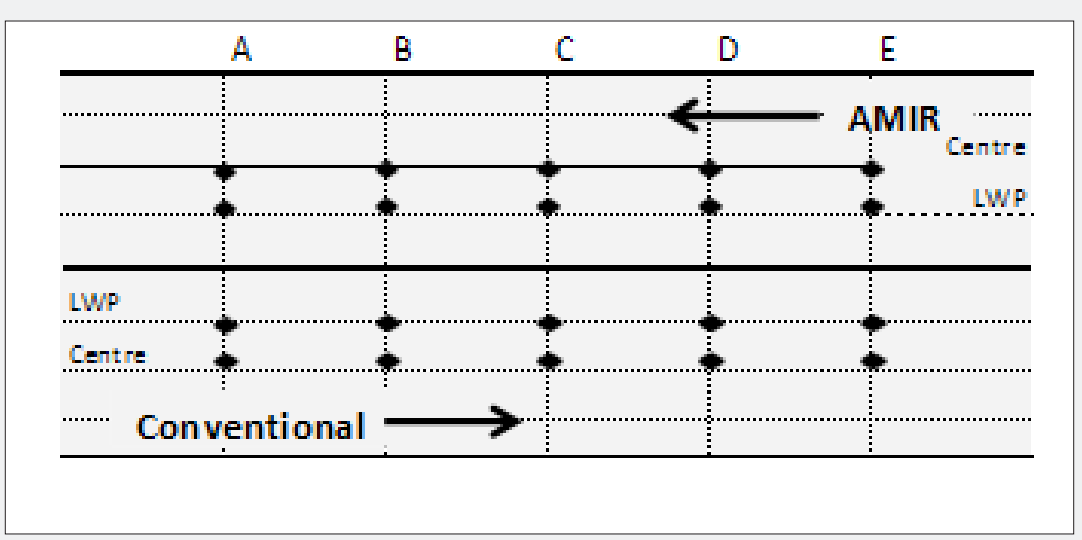

Figure 3: Site 1-Typical Layout of Pavement Texture Measurements (Ottawa Road).

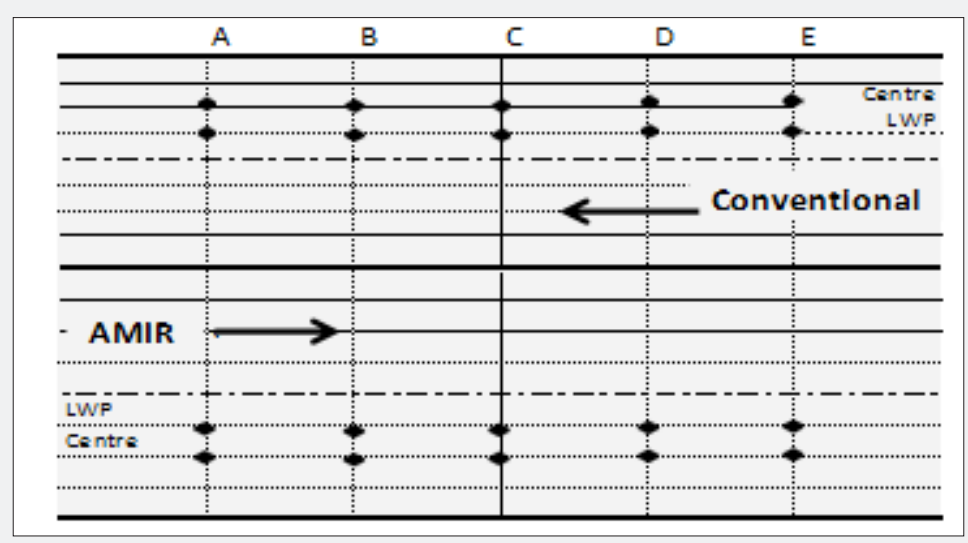

Figure 4: Site 2-Typical Layout of Pavement Texture Measurements (Kingston Bridge).

\section{skid resistance measurements}

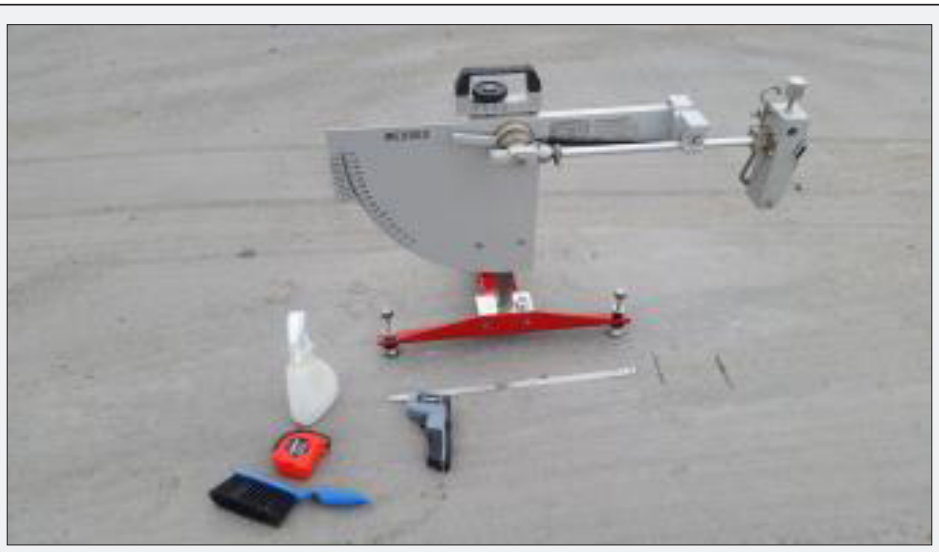

Figure 5: British pendulum tester

The British pendulum tester (BPT) was used for determining skid resistance of pavement surface. The test consists of measuring the energy loss when a rubber slider edge is propelled over a surface. The test followed the standard ASTM E303-93 [25]. Before performing the tests, the area measured was swept and the pendulum was leveled and checked. The checking process 
consisted of checking the zero setting of the equipment. This was done by releasing the pendulum arm and observing the pointer reading on the graduated scale. If the pointer reading past the zero position or did not reach the zero position, the rings in the centre of the equipment needed to be adjusted until the zero position is reached. Another adjustment necessary was adjusting the contact path length of each edge of the slider. The contact path length was $100 \mathrm{~mm}$. After all these checks, the equipment was ready to be used. The surface was sprayed with water and the pendulum arm was released from the horizontal position. The pendulum arm swung freely through its arc. The arm was caught before the slider touched the surface. The British Pendulum Number (BPN) was the reading indicated by the pointer on the graduated scale. The test was repeated until the results of four successive swings did not vary more than three scale units. Figure 5 shows the British Pendulum tester used for measuring skid resistance levels in the field.
The tests were performed for each of the points located on the road section. For each point four readings were recorded. The readings were averaged and corrected to the temperature of 20 ${ }^{\circ} \mathrm{C}$ using the equation Eq.1 given by the Australian standard WA 310.1 [26]. This correction was necessary to correct the effects of temperature on the slider rubber.

$$
B P N 20=\frac{B P N}{1-(0.00525(T-20))}
$$

Where:

The BPN20 = mean of the British Pendulum Number corrected to $20^{\circ} \mathrm{C}$

$$
\begin{aligned}
& \text { BPN = means of the British pendulum number } \\
& \mathrm{T}=\text { temperature of wetted pavement surface in }{ }^{\circ} \mathrm{C}
\end{aligned}
$$

\section{Macrotexture measurements}

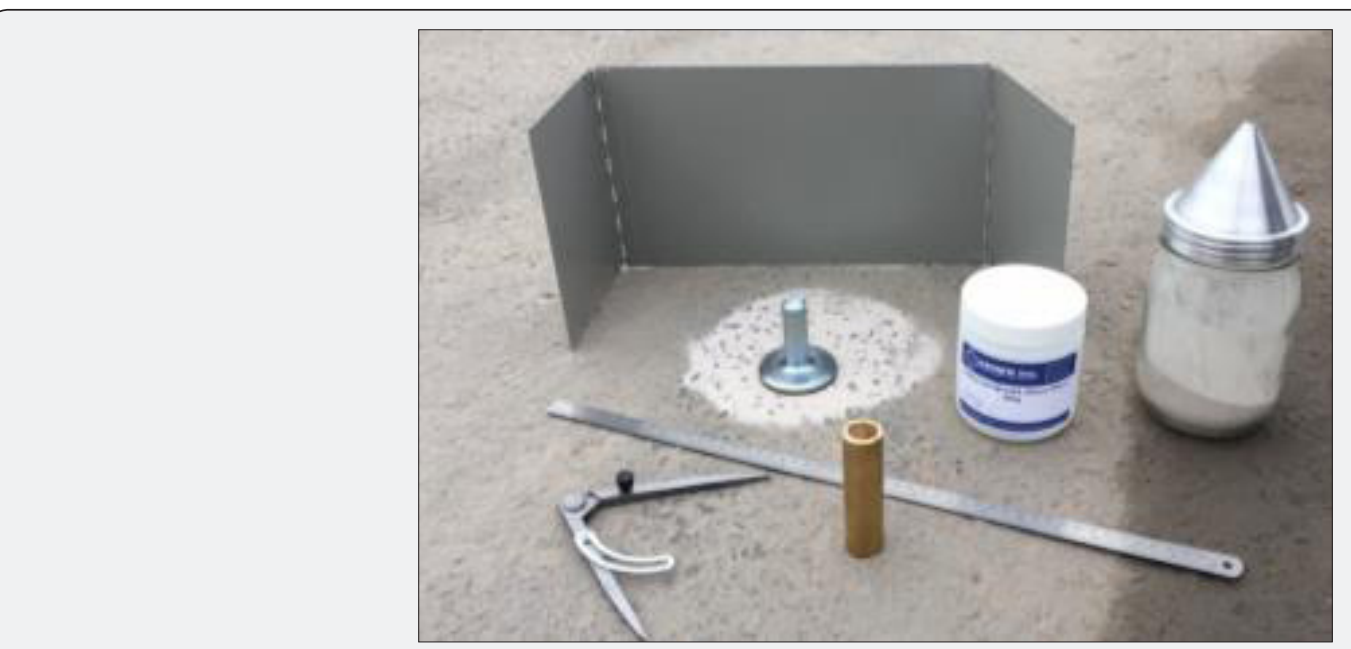

Figure 6: Sand patch apparatus.

The sand patch test is a volumetric test of measuring pavement macrotexture. The test followed the standard ASTM E965-15 [27]. The test consists of spreading a known volume of sand (Ottawa sand) on a dry pavement surface to form a circle., The voids in the pavement surface were filled with the sand. The diameter of the circle filled with sand was measured at four equally spaced locations. The measurements were averaged and used to calculate the mean texture depth (MTD) of the pavement surface section. The equations used for MTD calculation are given by Eq. 2 and Eq.3. Figure 6 shows the sand patch apparatus used for measuring macrotexture levels in the field.

$$
\begin{aligned}
& D=\frac{D 1+D 2+D 3+D 4}{4} \\
& M T D=\frac{4000 \mathrm{~V}}{\pi D^{2}}
\end{aligned}
$$

Where:

$(\mathrm{mm})$

D1, D2, D3, D4= diameters of the circle filled with sand

$$
\begin{aligned}
& \text { MTD = mean texture depth }(\mathrm{mm}) \\
& \text { V = volume of sand in millilitre }(\mathrm{ml}) \\
& \text { D = average diameter of sand patch in millimetres }(\mathrm{mm})
\end{aligned}
$$

The mean surface texture of the segment is given by the average of the MTDs using Eq.4

$$
\overline{M T D}=\frac{\sum M T D}{n}
$$

Where:

MTD = average of the mean texture depth of each point $\mathrm{n}=$ number of points measured in the section 


\section{Civil Engineering Research Journal}

\section{Results and Discussion}

The measurements of skid resistance and macrotexture were calculated using the measurements of the centre and left wheel path. The descriptive statistics of the measurements of skid resistance after temperature correction (BPN20) and macrotexture (MTD in $\mathrm{mm}$ ) per site and per roller type are summarized in Table 1. Figure $7 \& 8$ show the boxplot distribution with the minimum, median, and maximum of skid resistance and macrotexture values per site location and roller type.

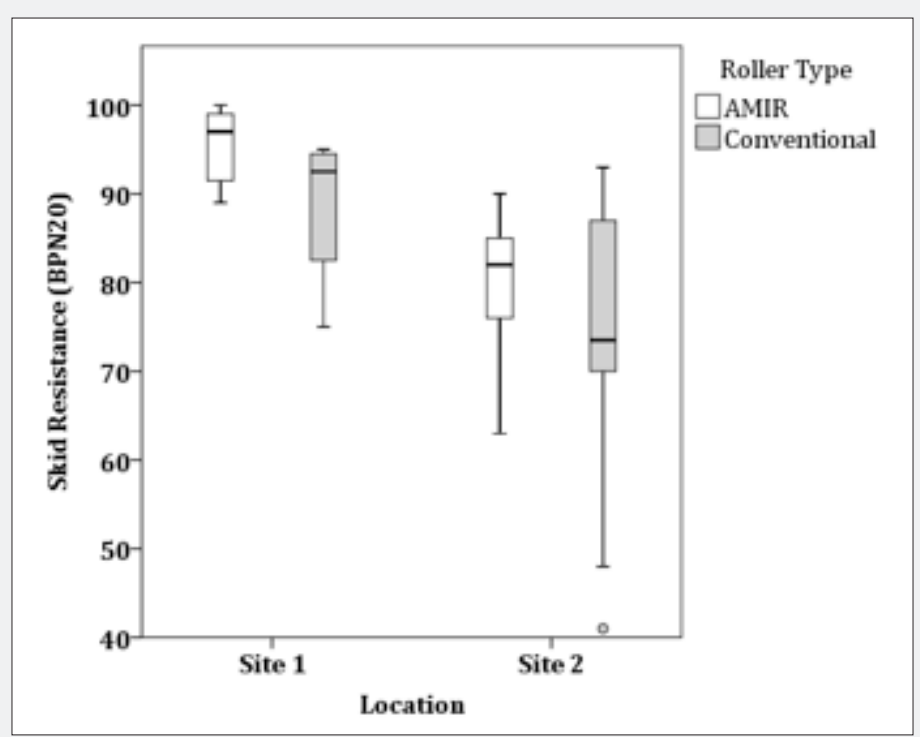

Figure 7: Skid Resistance per Location and per Roller Type.

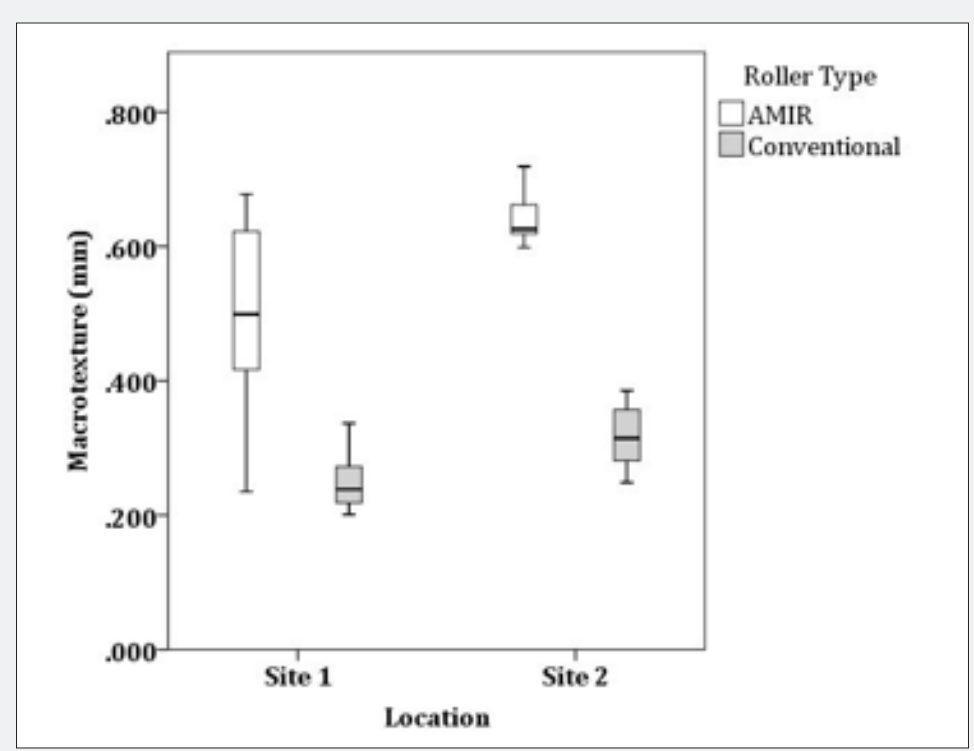

Figure 8: Macrotexture per Location and per Roller Type.

Table 1: Descriptive Statistics.

\begin{tabular}{|c|c|c|c|c|c|c|}
\hline \multirow{2}{*}{ Site } & \multirow{2}{*}{ Roller Type } & \multirow{2}{*}{ Pavement Textures } & \multicolumn{4}{|c|}{ Descriptive Statistics } \\
\hline & & & Maximum & Minimum & Mean & Std. Deviation \\
\hline \multirow{4}{*}{ Site 1} & \multirow{2}{*}{ AMIR } & BPN20 & 100 & 89 & 96 & 4 \\
\hline & & MTD (mm) & 0.6776 & 0.2351 & 0.4987 & 0.1488 \\
\hline & \multirow{2}{*}{ Conventional } & BPN20 & 95 & 75 & 89 & 9 \\
\hline & & MTD (mm) & 0.3367 & 0.2008 & 0.2494 & 0.0439 \\
\hline
\end{tabular}




\section{Civil Engineering Research Journal}

\begin{tabular}{|c|c|c|c|c|c|c|}
\hline \multirow{3}{*}{ Site 2} & AMIR & BPN20 & 90 & 63 & 80 & 8 \\
\cline { 3 - 7 } & \multirow{3}{*}{ Conventional } & MTD (mm) & 0.7188 & 0.5986 & 0.6404 & 0.0367 \\
\cline { 2 - 7 } & & BPN20 & 93 & 41 & 73 & 17 \\
\hline
\end{tabular}

A series of statistical T-tests for comparison of means were performed to compare measurements of skid resistance (BPN20) between the lanes compacted with the AMIR and the conventional steel roller. The results showed that there were statistical significant differences at $5 \%$ of the level of confidence (p-value $<0.05$ ) in the skid resistance measurements in the sections compacted with the AMIR and the conventional roller. The lanes compacted with the AMIR showed greater skid resistance than the lanes compacted with the conventional steel roller.

For site 1, the lane compacted with the AMIR showed BPN20 mean of 96 and standard deviation of 4 while the lane compacted with the conventional roller showed BPN20 mean of 89 and standard deviation of 9 . An improvement of $8.14 \%$ of the skid resistance was achieved by AMIR compactor in addition of less variability as described by the coefficient of variation (Std Deviation/Mean) of $4.2 \%$ to $10.1 \%$ of AMIR to steel compaction methods respectively.

For site 2, the lane compacted with the AMIR showed BPN20 mean of 80 and standard deviation of 9 while the lane compacted with the conventional roller showed BPN20 mean of 73 and standard deviation of 17. An improvement of $9.6 \%$ of the skid resistance achieved by AMIR compactor in addition of less variability as described by the coefficient of variation of $10 \%$ to $23.3 \%$ of AMIR to steel compaction methods respectively. The BPN20 values were compared with the BPN values used as reference by the European Commission Autralian, the Autralian Transport Road Research Laboratory, and the Department of Transportation of South Australia [20-22]. The Transport and Road Research Laboratory recommends a minimum BPN of 55 for wet surfaces with ADT over 2000. The European Commission and Australian Department of Transportation recommends a BPN of 45 for rural roads with maximum vehicle speed of $100 \mathrm{~km} / \mathrm{h}$. Thus, while AMIR method showed improved skid resistance. The two road sections met the minimum BPN values recommended by European Commission and the Australian Transport Road Research Laboratory and the Department of Transportation.

It should be mentioned that the Ontario Ministry of Transportation (MTO) does not use BPN as reference for skid resistance for Ontario roads. The MTO uses another indicator of skid resistance, skid number, as reference. The skid number (SN) is measured with another device, the Locked Wheel Trailer (LWT); therefore, it was not possible to compare skid resistance BPN with SN used by MTO. Another series of paired T-tests for means were conducted to compare measurements of macrotexture (MTD) between the AMIR the conventional roller. The results showed that there were statistical significant differences at $5 \%$ of the level of confidence ( $p$-value $<0.05$ ) in the macrotexture measurements in the road sections compacted with the AMIR and the conventional steel roller.

For site 1, the lane compacted with AMIR showed greater macrotexture than the lane compacted with the conventional steel roller. The lane compacted with AMIR showed MTD mean of $0.4987 \mathrm{~mm}$ with standard deviation of $0.1488 \mathrm{~mm}$ while the lane compacted the conventional steel roller showed MTD mean of $0.2494 \mathrm{~mm}$ with standard deviation of $0.0439 \mathrm{~mm}$. The AMIR method achieved 100\% improvement in the values of macrotexture and comparable variability as indicated by the coefficient of variation of $29.8 \%$ and $17.6 \%$ for AMIR and steel compaction methods, respectively.

For site 2, the lane compacted with AMIR showed greater macrotexture than the lane compacted with the conventional steel roller. The lane compacted with AMIR showed MTD mean of $0.6404 \mathrm{~mm}$ with standard deviation of $0.0367 \mathrm{~mm}$ while the lane compacted the conventional steel roller showed MTD mean of $0.3181 \mathrm{~mm}$ with standard deviation of $0.0447 \mathrm{~mm}$. The AMIR method achieved 101\% improvement in the values of macrotexture and comparable variability as indicated by the coefficient of variation of $5.7 \%$ and $14 \%$ for AMIR and steel compaction methods, respectively. The MTD values measured in the field were compared with the typical texture depths for new surfacing given by the Australian Guidelines for road surfacing [23]. In the Australian guidelines, the typical MTD for a dense graded asphalt $10 \mathrm{~mm}$ or larger is between $0.400 \mathrm{~mm}$ to $0.800 \mathrm{~mm}$ $[23,28]$. Therefore, the lanes compacted the AMIR were the only lanes that exhibited texture depths recommended by the Australian guidelines while the section finished with the steel roller fails to meet this requirement.

In addition to statistical analysis, differences of pavement surface textures were visually observed on road sections compacted with the AMIR and with the conventional steel roller. Figure $9 \& 10$ show pictures of pavement surfaces compacted with the AMIR and the conventional compaction. It can be observed that the AMIR-compacted pavement surface was smoother and tighter with aggregates more uniformly distributed than the pavement surface compacted with the conventional compaction. It can also be noted that the asphalt surface compacted with the AMIR was crack free, while the surface compacted with a conventional oscillating steel roller exhibited numerous cracks and crushed stones. 


\section{Civil Engineering Research Journal}

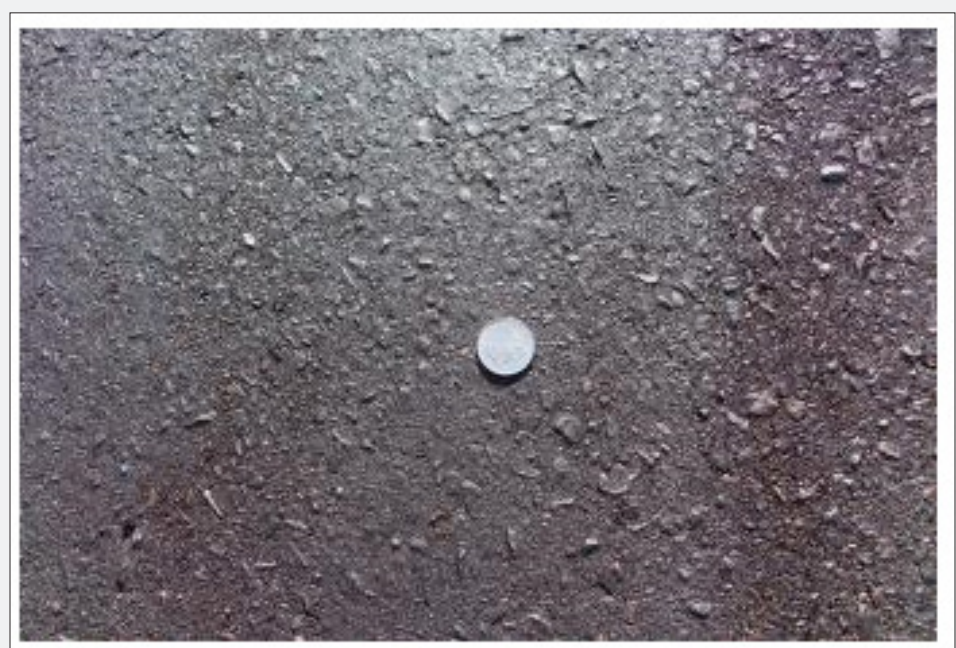

Figure 9: Asphalt Surface Texture Compacted with the AMIR.

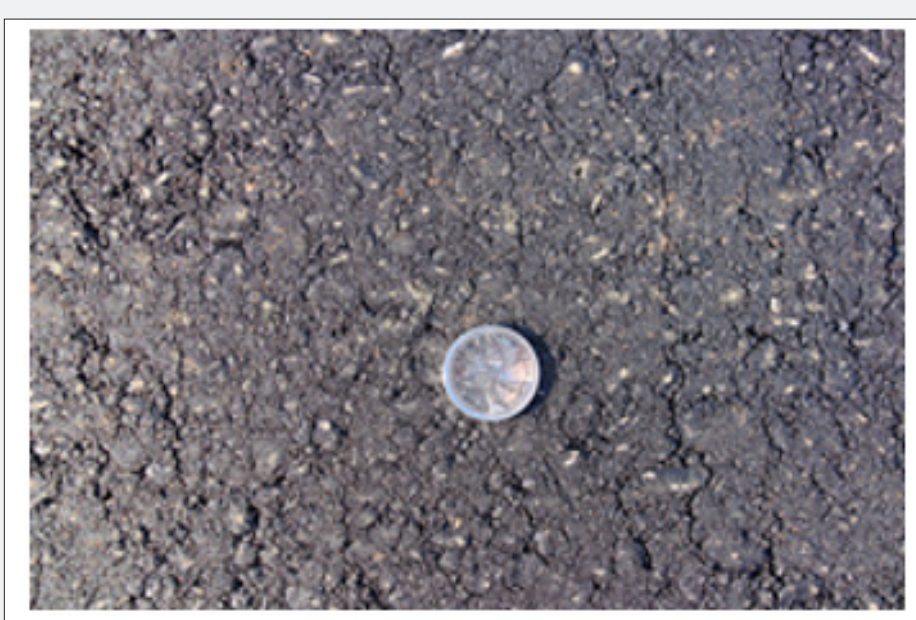

Figure 10: Asphalt Surface Texture Compacted with Conventional Rollers.

\section{Conclusion}

This study investigated the differences of skid resistance and macrotexture of asphalt pavement surfaces compacted with the AMIR and a conventional steel roller on road sections in the city of Ottawa and on bridge lanes of a bridge in the City of Kingston. The results showed that there were significant statistical differences in the measurements of skid resistance (BPN) and macrotexture (MTD) achieved by both compaction methods. The lanes compacted with AMIR roller showed skid resistance and macrotexture means were greater on lane compacted with the AMIR. The lanes compacted with AMIR roller exhibited texture depth that meets the recommended values for new surfacing given by the Australian Guidelines. In addition to less variation observed on the AMIR finished lanes the steel compacted section failed to meet Australian standards for acceptable macrotexture values. Clearly, better and uniform values of skid resistance and macrotexture achieved on asphalt roads regardless of the applied criterion ensures safer roads for travellers especially when travelling on wet roads.

\section{References}

1. Roberts FL, Kandhal PS, Brown ER, Lee DY, Kennedy TW (1996) Hot Mix Asphalt Materials, Mixture Design, and Construction. In: Lanham MD (Ed.), $\left(2^{\text {nd }}\right.$ edn), National Asphalt Paving Association Education Foundation, CA, USA.

2. Fromm H (1964) The Compaction of Asphaltic Concrete on the Road. Association of Asphalt Paving Technologists 33: 241-284.

3. Auditor General (2016) Ministry of Transportation-Road Infrastructure Contract Awarding and Over sighting. Auditor General Office, Toronto, Canada, p. 1-33.

4. Abd El Halim AO, Phang W, Haas R (1987) Realizing Structural Design Objectives Through Minimizing of Construction Induced Cracking, $6^{\text {th }}$ International Conference on Structural Design of Asphalt Pavements Ann Arbor, Michigan, University of Michigan, USA, pp. 965-970.

5. Abd El Halim AO, Phang W, Haas R (1993) Unwanted Legacy of Asphalt Pavement Compaction. Journal of Transportation Engineering, 119 (6): 914-932.

6. Abd El Halim AO, Mostafa A (2006) Asphalt Multi-Integrated Rollers and Steel Drum Compactors Evaluating Effect of Compaction on Permeability of Asphalt Pavements. Journal of the Transportation Research Board 1967: 173-180. 


\section{Civil Engineering Research Journal}

7. Abd El Halim AO, Dalia S, Abdelzaher M (2009) A Protection of the Environment through the Prevention of Surface Cracking. The Open Civil Engineering Journal 3: 7-15.

8. Abd El Halim AO, Pinder F, Chelliah AR, Abd El Halim A (2013) Reducing Maintenance and Rehabilitation Costs through the Use of AMIR Compaction. Civil Engineering and Architecture 1: 51-60.

9. International Organization for Standardization (2018) Characterization of Pavement Texture by Use of Surface Profiles-Part 2: Terminology and Basic Requirements Related to Pavement Texture Profile Analysis.

10. Kummer HW (1966) Research Equipment for the Study of Rubber Friction and Skid Resistance.

11. Hall JW, Smith KL, Titus-Glover L, Wambold JC, Yager TJ, et al. (2009) Guide for pavement friction. NCHRP Project, Washingto, USA, p. 1-43.

12. Noyce DA, Yambo J, Chapman J, Bill A (2007) Incorporating road safety into pavement management: maximizing surface friction for road safety improvements. University of Wisconsin, Madison, USA.

13. American Association of Highway and Transportation Officials (2008) Guide for Pavement Friction, Washington, USA.

14. Highways England (2015) Skidding Resistance, HD 28/04, Design Manual for Roads and Bridges (DMRB)", 7-3, Part 1. Highways Agency, Norwich, Norfolk, England.

15. Glennon JC, Hill PF (2004) Roadway Safety and Tort Liability. Lawyers \& Judges Publishing Company Inc, Tucson, Arizona, USA.

16. Li S, Noureldin S, Zhu K (2010) Macrotexture and Microtexture Testing Using Laser Sensors. Joint Transportation Research Program. Indiana Department of Transportation and Purdue University, West Lafayette Indianapolis, Indiana, USA.

17. McDaniel RS, Kowalski KJ (2012) Investigating the Feasibility of Integrating Pavement Friction and Texture Depth Data in Modeling for INDOT PMS. Joint Transportation Research Program, Indiana Department of Transportation and Purdue University, West Lafayette, Indiana, USA.
18. Kamel N, Gartshore T (1982) Ontario's Wet Pavement Acciden Reduction Program. In: Hayden CM, (Ed.), Pavement Surface Characteristics and Material. Baltimore: ASTM Special technical Publication 763: 98-117.

19. Transportation Association of Canada (1977) Pavement Design and Management Guide. Ottawa, Canada.

20. (2011) Commission Regulation (EU) 228/2011 of 7 March 2011 establishing amending Regulation (EC) 1222/2009 of the European Parliament and of the Council with regard to the wet grip testing method for C1 tyres (2011). Official Journal of the European Union, L62, France, p. 1-16.

21. TRRL (1969) Instructions for using the portable skid resistance tester Transport and Road Research Laboratory, Bershire, Australia.

22. TN24 (2016) Road Surface Friction Skid Resistanc \& Pavement Texture) Recommended Investigatory Levels. Department of Planning Transport and Infrastructure of South Australia, South Australia.

23. (2003) Guide to the Selection of Road Surfacing, AP-G-63-03. Austoroads, Sydney, Australia.

24. Highways Agency (2005) Interim Advice Notes: Traffic speed condition surveys: Revised assessment criteria (IAN 42/05).

25. ASTM E303-93(2013) Standard Test Method for Measuring Surface Frictional Properties Using the British Pendulum Tester. ASTM International, West Conshohocken, PA, USA.

26. WA 310.1-2012 (2012) Pavement Skid Resistance: British Pendulum Method. Main Roads Western Australia. Waterloo Crescent, East Perth, Australia.

27. ASTM E965-15 (2015) Standard Test Method for Measuring Pavement Macrotexture Depth Using a Volumetric Technique. ASTM International, West Conshohocken, PA, USA.

28. ASTM E965-15 (2015) Standard Test Method for Measuring Pavement Macrotexture Depth Using a Volumetric Technique. ASTM International, West Conshohocken, PA, USA.

\section{Your next submission with Juniper Publishers will reach you the below assets}

- Quality Editorial service

- Swift Peer Review

- Reprints availability

- E-prints Service

- Manuscript Podcast for convenient understanding

- Global attainment for your research

- Manuscript accessibility in different formats

( Pdf, E-pub, Full Text, Audio)

- Unceasing customer service

Track the below URL for one-step submission https://juniperpublishers.com/online-submission.php 